\title{
Studies on the carrying capacity of water resources for sustainable cities in the Taijiang area
}

\author{
Y. C. Lin $^{1} \&$ T. Y. Lee ${ }^{2}$ \\ ${ }^{I}$ Department of Leisure Resources and Green Industries, \\ Leader University, Taiwan \\ ${ }^{2}$ Department of Information Communication, Leader University, Taiwan
}

\begin{abstract}
Water resource problems have become increasingly severe with the onslaught of global warming. This has shifted focus gradually to the carrying capacity of water resources. Discussions on the carrying capacity of water resources involve the water load capacity required by and supplied for industrial and agriculture use, living water, and environment protection under social, technological, and economic conditions toward the aim of achieving sustainable development of living, ecology and production.

This study is aimed at discussing the utilization and configuration of water resources in Taijiang District from the perspective of sustainable development, as well as the demand and supply of water resources in the region for the point of view of water balance. This study collected data related to demand and supply of water resources in Taijiang District from 1992 to 2006. Water demand data included the amount of water for livelihood, industry, agriculture and ecological use. This study also utilized the grey system theory to predict the amount of water utilization from 2014 to 2019 . Results show that the demand and supply of water resources in Taijiang District currently present a negative tendency. The demand and supply of water resources in Taijiang District is predicted to arrive at a positive tendency. This can be accomplished by utilizing the grey system, which predicts the amount of future water utilization under each target. In addition, working with planning and allocation of water resources issued by the Water Resources Agency, Ministry of Economic Affairs, which increased the amount of water resources supply to the whole Taijiang District, is also necessary.
\end{abstract}


Keywords: carrying capacity of water resources, sustainable indicator, grey system theory.

\section{Introduction}

An ideal sustainable urban and rural area should be one that is self-sufficient and with a supply of natural resources independent of other areas, particularly with regards to self-sufficiency on water and energy resources. A sustainable urban area should be equipped with full survival capability and have a balanced energy output. Nature preservation adheres to the minimum demand principle that diminishes or reduces wastes. Therefore, development of sustainable urban and rural areas should pay special attention to the integrity and soundness of structures in the biological system, and should regard health and biological diversity, green land, rivers, and water systems as measurement indicators of these factors. Often, excessive design and artificialization cause cities to lose their natural ecology, contributing instead to environmental damage, particularly through various types of pollution caused by human activities. These types of pollution challenge the tolerability of the ecological environment toward human

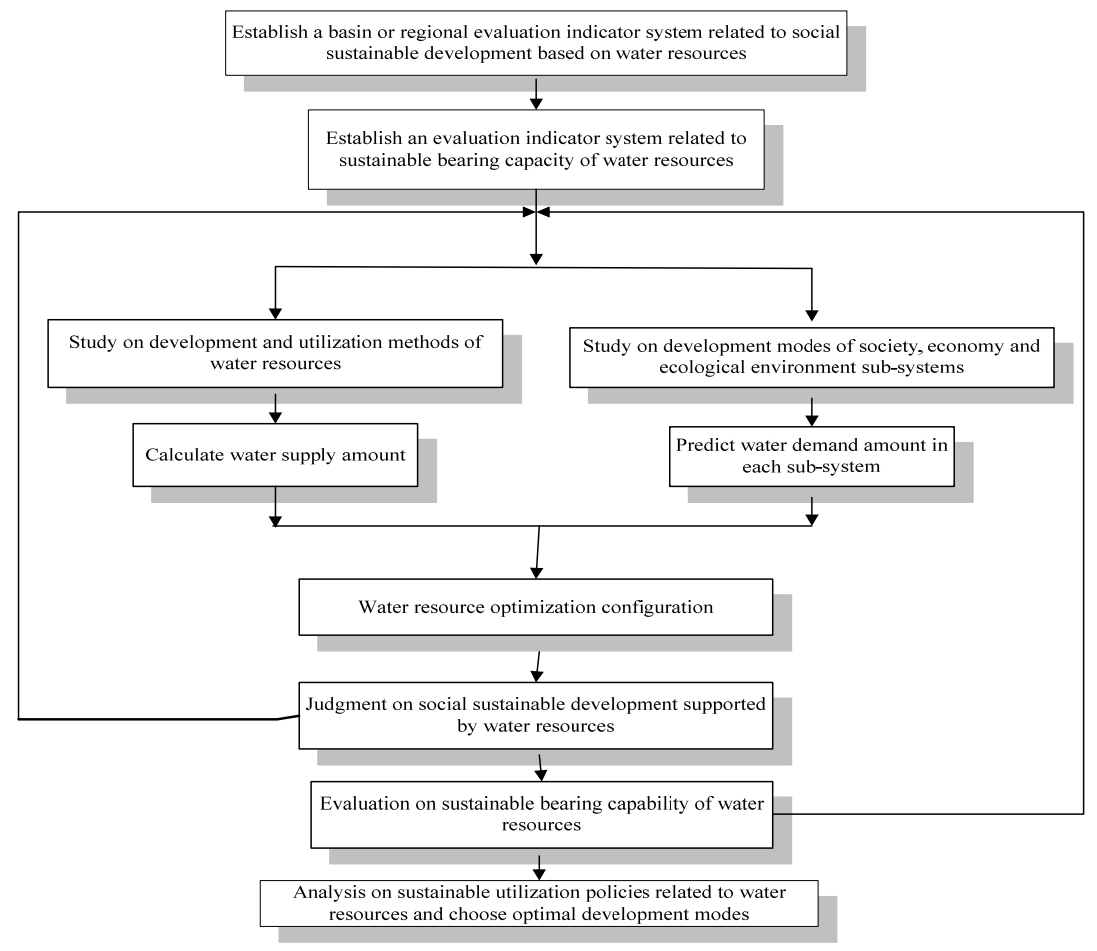

Figure 1: Construction diagram of sustainable development of water resources. 
activities. From the perspective of evolution and development of urban and rural areas, the implementation of reform on construction energy, water resources planning, and special construction in all directions has become urgent.

The ratio of water occupancy in urban-region matter structures is above $90 \%$; thus, water circulation should be at the forefront of sustainable development theory. Topics related to water are centralized into one comprehensive view concerning nature and human water system with resource management, including monitoring the water quality of rivers, underground water, wastewater, and drain water. Therefore, sustainable development of water resources covers a wide range of issues, including social and economic mode and water resource development and distribution, which have been discussed with the view of sustainable living, production, and ecology (Fig. 1).

Dong [1] pointed out that water is an indispensable commodity for humans and all living creatures; it is also a significant and irreplaceable resource in terms of industrial and agricultural production, economic development, and environmental protection. Jenerette [4] described the current biggest challenge in urban areas in the world: guaranteeing continuous water supply. In future, water consumption modes in urban regions will be subject to changes occurring in the population centralized area, average utilization of water resources by people, and water utilization in climate and ecological systems.

In 2003, Zhang Li [7] stated that the bearing capability of water resources is composed of three parts: bearing capacity of water resource quantity, bearing capacity of water environment, and regionally defined capability of water hazards. Wen [6] advocated regional development and stated that this development must abide with natural law by considering the bearing capacity of water resources.

\section{Study area description}

Taijiang District comprises a region extending from the west of Ximen Road to Anping, Annan, and Qigu Districts (Fig. 2). The Taijiang inland sea occupies an area of $1,050 \mathrm{~km}^{2}$ and extends to the north gate of Tainan County in the north, Ercenghang Stream in the south, the east bank of Bei Xianwei Island in the west, and Chihkan Tower in the east, with multiple rivers flowing into the territory. Taijiang has long been the political, military, educational, and cultural centre of the district. Its north district has been developed into a comprehensive living and commerce area. Although various industries have moved outward to the Anping industrial area, it has also become a tourist attraction due to the transformation of the Anping Harbour into a sightseeing fishery harbour. In addition, Yizai Golden City and Anping Old Castle also attract a number of tourists. The onshore area west of the Annan District was previously the centre of the aquaculture industry and was the site of salt farmlands. However, since the development of 2000 hectares of land into the Tainan Science Industrial Park in 1996, plans have been made to use the residual fragmentary land to build the Sicao Wildlife Reserve. The most common industry in the east district of Annan is agriculture. Some earlier communities have become comprehensive areas integrating living, commerce, and light industries. 


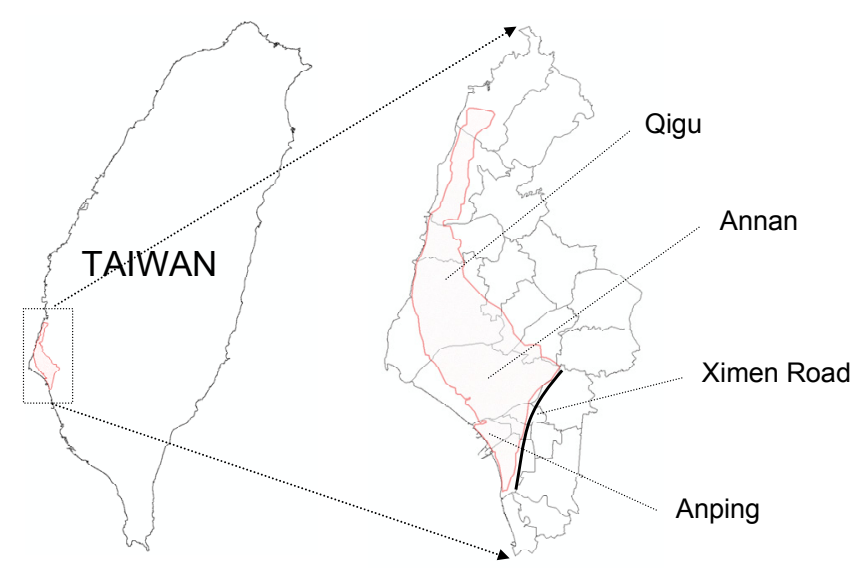

Figure 2: $\quad$ Range diagram of research regions.

\section{Bearing capacity of water resources}

\subsection{Indicator of bearing capacity of water resources}

Bearing capacity is generally defined in ecology as "the maximal quantity of a certain species supported by a particular environment."

Bearing capacity of water resources are discussed mainly in terms the balance of two aspects: support and pressure. Support discusses items of water resources in terms of water supply in the studied region, including total amount of water resources, average water use amount per capita, development of water resource, allocation of passing water bodies, and degree of water pollution. Pressure discusses items of water resources in terms of the water utilization targets in studied region, including population development, social and economic development, and ecological environment. Items that have different amounts of water utilization under these three dimensions are described in the following. Utilization and allocation of water resources should consider the current population scale within the region, the subsequent growth ratio of the population, and population development. Promotion of economic and social development should be also expanded based on the increment of population, agriculture, and industry. The population factor, along with the amount of water utilization for agriculture and other industries, will increase the quantity of water resources used substantially. The ecological environment should also be considered. These three dimensions constitute the pressure aspect for overall water resources. Each indicator is shown in Fig. 3.

To obtain an understanding of the balance of the bearing capacity in terms of the entire water resource, the following calculation formulas for each indicator were used. 


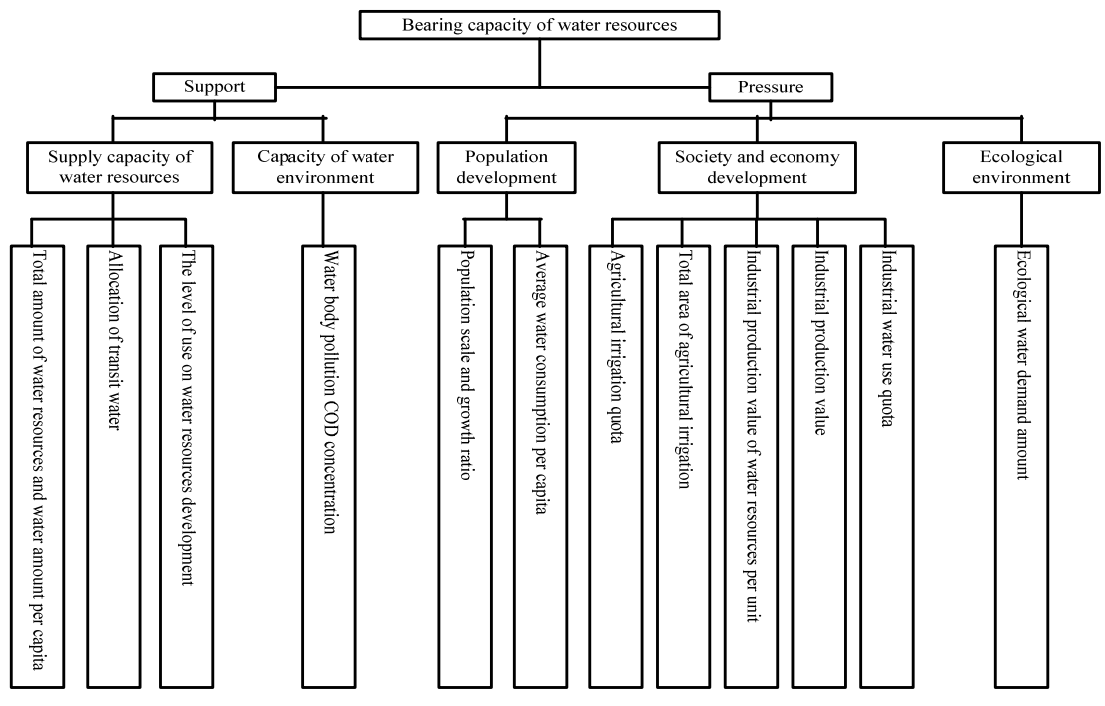

Figure 3: $\quad$ Bearing capacity indicator system of water resources.

1. Total amount of water resources supply $(W)$

$$
W=W_{l}+W_{r}
$$

where $W_{l}$ is the total amount of surface and underground water recoverable in the process of water circulation in a basin, and $W_{r}$ is the amount of water transferred from cross-basins.

\section{Livelihood water $\left(W_{P}\right)$}

Livelihood water refers to water that comes from tap water supply and selfsupply. Self-supply water items are not included in various statistics; thus, the survey on livelihood water includes only the amount of water supplied by water corporations.

\section{Agricultural water $\left(W_{A}\right)$}

Agricultural water includes water used for farmland irrigation, animal husbandry, and aquaculture. The calculations are described as follows.

\section{a. Farmland irrigation water}

Farmland can be divided into drought and paddy farmlands. Paddy farmlands include first and second crops. This study calculates the amount of water utilization according to plantation area in each phase of the crop, as well as the amount of irrigation water in each different area per unit.

b. Animal husbandry water

Animal husbandry water $=\sum$ (Amount of water used per animal husbandry unit

$$
\times \text { Number of animals per animal husbandry unit) }
$$


c. Aquaculture water

$$
Q\left(\mathrm{~m}^{3} / \mathrm{s} / \text { day }\right)=\frac{\text { Daily water demand amount }\left(\mathrm{m}^{3}\right)}{\text { Daily water use time }(\mathrm{h}) \times 60(\mathrm{~min} / \text { hour }) \times 60(\mathrm{~s} / \mathrm{min})}
$$

4. Industrial water $\left(W_{I}\right)$

Industrial water is generally divided into cooling, manufacturing, and boiler waters as well as employee water in the factory and other water applications.

Industrial annual water use $=$ amount of water used daily per unit area $\times$ industrial area $\times$ number of annual working days

5. Ecological water demand amount $\left(W_{E}\right)$

Environmental and ecological water demand is the water required for the maintenance, protection and improvement of the natural and ecological environment [2, 3]. Zhang et al. [8] proposed that the amount of ecological water demand is dependent on natural supplemental waters. If the amount of ecological water demand is calculated into the amount of water used in the whole studied region, a ratio of $10 \%$ (by which environmental water demand amount takes up living water demand amount) will be used into the predicted calculation.

6. Total amount of water resources demand $\left(W_{D}\right)$

$$
W_{D}=W_{P}+W_{A}+W_{I}+W_{E}
$$

where $W_{P}$ is the amount of population water demand; $W_{I}$ is the amount of industrial water demand; $W_{A}$ is the amount of agricultural water demand; and $W_{E}$ is environmental demand and other water demand amounts.

Total amount of water resources in the entire studied region was calculated by summing up the livelihood, industrial, agricultural, and ecological water use surveyed. Analysis on water utilization amounts in each target from 1992 to 2006 is shown in Table 1. Results show that the supply and demand of water resources in the entire Tiajiang District was not balanced from 1992 to 2006. Water use amount significantly decreased from 2005 to 2006 (Fig. 4), inducing the supply and demand gap to shrink. Results indicate that supply amount of water resources have to be increased to overcome the issue of the insufficiency of water resources.

\section{Rate of water quality of rivers up to the standard}

Characteristics of water quality in rivers can be presented by a single indicator or a set of comprehensive indicators. Commonly used single indicators include biochemical oxygen demand, dissolved oxygen, ammonia nitrogen, and suspended solids. Comprehensive indicators include water quality indicator (WQI), river pollution indicator (RPI), rate of water quality up to the standard that are usually used to evaluate water quality, and pollution status of rivers. By screening indicator pollutants and analyzing major items controlling water quality (e.g., rate of water quality up to the standard), these factors can be applied as references in planning measures to decrease river pollution. Table 2 shows that, 
in four items, the rate of water quality up to the standard in Tseng-Wen River was higher than those in Yanshuei River. Water quality in Tseng-Wen River tended to improve gradually, whereas water quality in Yanshuei River still needed improvement.

Table 1: Water utilization amount under each target in the studied region.

Unit: 1 million cubic meters

\begin{tabular}{|c|c|c|c|c|c|}
\hline \multirow{2}{*}{ Year } & \multicolumn{4}{|c|}{ Water Utilization Programs } & \multirow{2}{*}{ In total } \\
\cline { 2 - 5 } & Industry & Agriculture & Livelihood & Ecology & \\
\hline 1992 & 23.57 & 565.73 & 85.43 & 8.54 & 683.29 \\
\hline 1993 & 18.48 & 560.99 & 85.18 & 8.52 & 673.17 \\
\hline 1994 & 17.04 & 603.06 & 84.97 & 8.50 & 713.56 \\
\hline 1995 & 17.14 & 583.72 & 73.18 & 7.32 & 681.35 \\
\hline 1996 & 16.89 & 596.36 & 79.27 & 7.93 & 700.45 \\
\hline 1997 & 14.97 & 529.83 & 79.44 & 7.94 & 632.18 \\
\hline 1998 & 15.00 & 452.57 & 87.24 & 8.72 & 563.53 \\
\hline 1999 & 15.01 & 454.30 & 100.40 & 10.04 & 579.75 \\
\hline 2000 & 18.14 & 452.70 & 89.86 & 8.99 & 569.69 \\
\hline 2001 & 18.16 & 458.33 & 97.47 & 9.75 & 583.72 \\
\hline 2002 & 40.08 & 622.95 & 90.83 & 9.08 & 762.95 \\
\hline 2003 & 17.55 & 383.00 & 92.61 & 9.26 & 502.42 \\
\hline 2004 & 18.32 & 384.79 & 93.08 & 9.31 & 505.49 \\
\hline 2005 & 17.94 & 415.54 & 96.15 & 9.61 & 539.24 \\
\hline 2006 & 18.98 & 361.21 & 98.32 & 9.83 & 488.34 \\
\hline
\end{tabular}

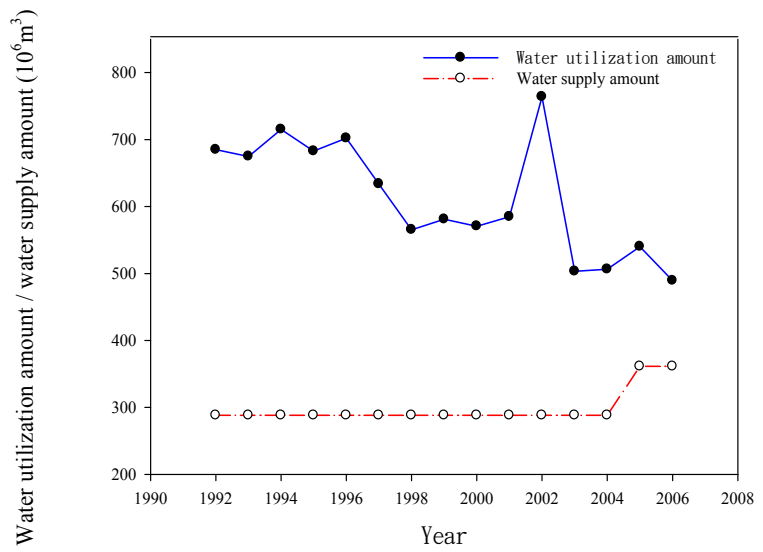

Figure 4: $\quad$ Supply and demand data diagram of water in Taijiang District. 
Table 2: $\quad$ Standard of water quality.

\begin{tabular}{|c|c|c|c|c|c|c|c|c|c|c|}
\hline \multirow{2}{*}{ Item } & \multicolumn{2}{|c|}{ DO } & \multicolumn{2}{c|}{ BOD $_{5}$} & \multicolumn{2}{c|}{ SS } & \multicolumn{2}{c|}{ NH3-N } & \multicolumn{2}{|c|}{$\begin{array}{c}\text { Up to standard } \\
(\%)\end{array}$} \\
\hline Rivers & $\begin{array}{l}\text { Tseng } \\
\text {-Wen }\end{array}$ & $\begin{array}{c}\text { Yan- } \\
\text { shuei }\end{array}$ & $\begin{array}{c}\text { Tseng } \\
\text {-Wen }\end{array}$ & $\begin{array}{l}\text { Yan- } \\
\text { shuei }\end{array}$ & $\begin{array}{c}\text { Tseng } \\
\text {-Wen }\end{array}$ & $\begin{array}{c}\text { Yan- } \\
\text { shuei }\end{array}$ & $\begin{array}{c}\text { Tseng } \\
\text {-Wen }\end{array}$ & $\begin{array}{c}\text { Yan- } \\
\text { shuei }\end{array}$ & $\begin{array}{c}\text { Tseng } \\
\text {-Wen }\end{array}$ & $\begin{array}{c}\text { Yan- } \\
\text { shuei }\end{array}$ \\
\hline 2002 & 89.1 & 31.9 & 73.3 & 40.0 & 53.3 & 56.9 & 60.8 & 20.0 & 29.2 & 13.3 \\
\hline 2003 & 88.0 & 23.6 & 50.0 & 38.3 & 57.5 & 76.4 & 68.3 & 20.0 & 29.2 & 16.7 \\
\hline 2004 & 95.4 & 28.0 & 51.9 & 23.8 & 47.2 & 89.3 & 69.4 & 19.0 & 26.9 & 17.5 \\
\hline 2005 & 92.4 & 45.8 & 76.4 & 50.0 & 43.8 & 72.2 & 80.6 & 30.0 & 25.0 & 11.7 \\
\hline 2006 & 92.9 & 51.4 & 81.4 & 41.7 & 46.5 & 65.3 & 77.5 & 26.7 & 35.3 & 15.0 \\
\hline 2007 & 93.6 & 51.4 & 80.9 & 41.7 & 46.8 & 61.1 & 80.9 & 25.0 & 35.5 & 16.7 \\
\hline 2008 & 95.6 & 65.3 & 86.8 & 60.0 & 68.4 & 75.0 & 82.4 & 31.7 & 44.9 & 13.3 \\
\hline
\end{tabular}

\subsection{Application of grey system theory in water utilization prediction}

The grey prediction model aims to discuss systems with insufficient information, and fully utilize this limited data in an analysis, with a good prediction capability. The following describes the model construction of grey prediction model. For the one-level differential equation of $\operatorname{GM}(1,1)$ the model is

$$
\frac{d x^{(1)}}{d t}+a x^{(1)}=b
$$

where $t$ is time, and $a$ and $\mathrm{b}$ are the coefficients. Original sequences are

$$
X^{(0)}=\left(x^{(0)}(1), x^{(0)}(2), \ldots, x^{(0)}(n)\right)
$$

An accumulated generation operation (AGO) toward original sequences should be conducted to provide intermediate information for model construction and to weaken the randomness of original sequences. Additionally, $X(1)$ is defined as AGO number sequence of $X^{(0)}$ :

$$
X(1)=\left(X^{(1)}(1), X^{(1)}(2), \ldots, X^{(1)}(n)\right)=\left(\sum_{K=1}^{1} X^{(0)}(K), \sum_{K=1}^{2} X^{(0)}(K), \ldots, \sum_{K=1}^{n} X^{(0)}(K)\right)
$$

Coefficients were acquired from Formulas (7) and (8), and by the adopting least-squares method. The approximate relation is acquired from solving Formula (6):

$$
\hat{X}^{(1)}(k+1)=\left[X^{(0)}(1)-\frac{b}{a}\right] e^{-a k}+\frac{b}{a}
$$

where $X^{(1)}(1)=X^{(0)}(1)$. Sequences were conducted using inversed-AGO (IAGO), as seen in Formula (10):

$$
\hat{X}^{(0)}(k)=\left[x^{(0)}(1)-\frac{b}{a}\right] e^{-a(k-1)}\left(1-e^{a}\right)
$$


where $k=1,2, \ldots, n$. An accuracy test should be conducted to understand the error between predicted values with actual value. Residual test method is described as follows:

$$
e(k)=\left|\frac{x^{(0)}(k)-\hat{x}^{(0)}(k)}{x^{(0)}(k)}\right| \times 100 \%, \quad k=2,3, \ldots, n
$$

If the average accuracy of $1-e(k)$ is above $90 \%$, it has a good prediction performance.

The $\mathrm{a}$ and $\mathrm{b}$ values in Formula (6) of each target is known by adopting the grey theory mode and through putting these values into formulas; the predicted values of water use amount of the Tiajiang District under each target from 2014 to 2019 can then be acquired (Table 3 ).

The Water Resources Agency has planned for 80,000 tons/d water to be supplied from Nanhua Reservoir to Kaohsiung in 2010, diverting 130,000 tons/d from Tseng-Wen Basin and supporting 70,000 tons/d to the Gaoping area after 2012. Statistical amounts of transferred water in Yufeng Dam, as well as the Tseng-Wen, Wushantou, and Nanhua Reservoirs and the Gaoping area, were obtained through calculations (Table 4). Supply and demand water amounts were predicted to achieve sufficiency in water resources after 2012 (Fig. 5).

Table 3: $\quad$ Predicted amount of water use for each target.

Unit: 1 million cubic meters

\begin{tabular}{|c|c|c|c|c|c|}
\hline Year & Industry & Agriculture & Livelihood & Ecology & $\begin{array}{c}\text { Total amount of water } \\
\text { utilization predicted }\end{array}$ \\
\hline 2007 & 16.04 & 347.86 & 106.47 & 15.97 & 486.35 \\
\hline 2008 & 15.97 & 334.24 & 109.07 & 16.36 & 475.65 \\
\hline 2009 & 15.91 & 321.16 & 111.73 & 16.76 & 465.55 \\
\hline 2010 & 15.84 & 308.59 & 114.45 & 17.17 & 456.05 \\
\hline 2011 & 15.77 & 296.51 & 117.24 & 17.59 & 447.11 \\
\hline 2012 & 15.70 & 284.91 & 120.10 & 18.02 & 438.72 \\
\hline 2013 & 15.63 & 273.76 & 123.03 & 18.46 & 430.87 \\
\hline 2014 & 15.56 & 263.04 & 126.03 & 18.91 & 423.54 \\
\hline 2015 & 15.50 & 252.75 & 129.11 & 19.37 & 416.71 \\
\hline 2016 & 15.43 & 242.85 & 132.25 & 19.84 & 410.37 \\
\hline 2017 & 15.36 & 233.35 & 135.48 & 20.32 & 404.51 \\
\hline 2018 & 15.29 & 224.21 & 138.78 & 20.82 & 399.11 \\
\hline 2019 & 15.23 & 215.44 & 142.17 & 21.33 & 394.16 \\
\hline Mean & 15.63 & 276.82 & 123.53 & 18.53 & 434.52 \\
\hline Min. & 16.04 & 347.86 & 142.17 & 21.33 & 486.35 \\
\hline Max. & 15.23 & 215.44 & 106.47 & 15.97 & 394.16 \\
\hline
\end{tabular}


Table 4: $\quad$ Total amount of water supply predicted in 2007-2019.

Unit: 1 million cubic meters

\begin{tabular}{|c|c|c|c|c|c|}
\hline Year & $\begin{array}{c}\text { Yufeng } \\
\text { Dam }\end{array}$ & $\begin{array}{c}\text { Tseng-Wen and } \\
\text { Wushantou } \\
\text { Reservoirs }\end{array}$ & $\begin{array}{c}\text { Nanhua } \\
\text { Reservoir }\end{array}$ & $\begin{array}{c}\text { Transferred } \\
\text { water }\end{array}$ & $\begin{array}{c}\text { Total water } \\
\text { amount of supply } \\
\text { predicted }\end{array}$ \\
\hline 2007 & 10.95 & 94.9 & 255.5 & 0 & 361.35 \\
\hline 2008 & 10.95 & 94.9 & 255.5 & 0 & 361.35 \\
\hline 2009 & 10.95 & 94.9 & 255.5 & 0 & 361.35 \\
\hline 2010 & 10.95 & 94.9 & 284.7 & 0 & 390.55 \\
\hline 2011 & 10.95 & 94.9 & 284.7 & 0 & 390.55 \\
\hline 2012 & 10.95 & 142.35 & 284.7 & 25.55 & 463.55 \\
\hline 2013 & 10.95 & 142.35 & 284.7 & 25.55 & 463.55 \\
\hline 2014 & 10.95 & 142.35 & 284.7 & 25.55 & 463.55 \\
\hline 2015 & 10.95 & 142.35 & 284.7 & 25.55 & 463.55 \\
\hline 2016 & 10.95 & 142.35 & 284.7 & 25.55 & 463.55 \\
\hline 2017 & 10.95 & 142.35 & 284.7 & 25.55 & 463.55 \\
\hline 2018 & 10.95 & 142.35 & 284.7 & 25.55 & 463.55 \\
\hline 2019 & 10.95 & 142.35 & 284.7 & 25.55 & 463.55 \\
\hline
\end{tabular}

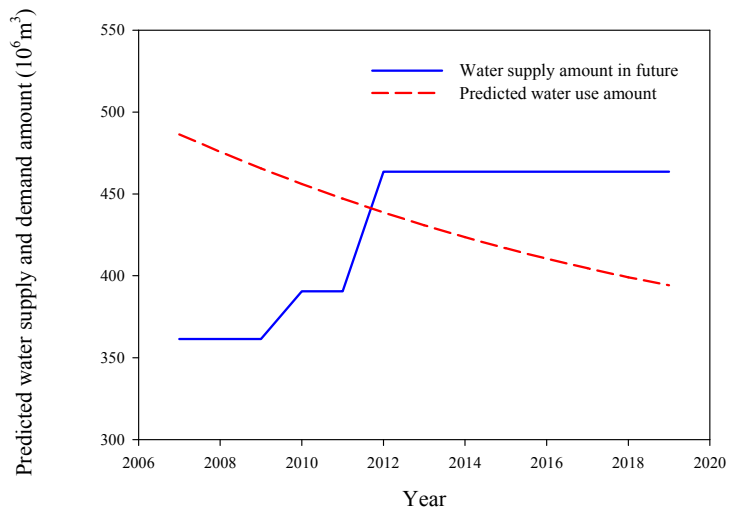

Figure 5: Supply and demand balance diagram of water utilization prediction in the future.

\section{Summary}

1. An analysis of the bearing capacity of water resources in Taijiang District shows that the amount of supply and demand waters tended to be unbalanced from 1992 to 2006. Allocation problems of water resources occurred 
throughout the country due to changes in social and economic industries and climate factor. This has led to partial farmland cultivation, which adopts rotational irrigation system, to lessen the amount of water use. However, population data shows that because the population in the entire Taijiang District increases gradually, relatively, livelihood water will also increase. Therefore, there a need for the allocation of overall water resources to be replanned.

2. Regarding insufficiency of water resources, the Water Resources Agency has stipulated plans related to water supply from Nanhua Reservoir to Kaohisung, water diversion from the Tseng-Wen Reservoir through the cross-basin, as well as water support to Laonong Stream in the Gaoping area, with the aim of increasing water supply in the entire Taijiang District. This study adopted the grey module to predict the amount of water use in the entire Taijiang District from 2007 to 2019. Results show that after transferred water is included, the supply and demand tendency of water in Taijiang District is expected to reach positive level.

3. Bearing capacity of water resources was not only evaluated through the water supply and demand, but also from the perspective of the quality of water resources, which affects supply amount indirectly. Thus, discussion on water quality is one of the bearing capacity indicators of water resources. This study discussed the most influential rivers and reservoirs in the studied region. Water quality in rivers is affected either by ecology or self-supply users. However, data shows that water quality in the whole studied region was acceptable despite the occurrence of pollutions, which affect water supply amount and water quality of the reservoirs. Data shows that the supply reservoir in Taijiang District could be classified as mesotrophic, whereas the eutrophic phenomenon occurred in Nanhua Reservoir in 2006. Water quality indirectly affects water supply; thus, reservoirs should be strictly controlled to prevent its water supply from being affected and increasing the burden on the bearing capacity on the entire water resources.

4. Although water utilization in Taijiang District seems to show a positive future trend, various development programs, population growth, and climate change should be still considered. Water supply in the whole Taijiang District should not only depend on transfer. Strengthening water-use allocation within the region, providing auxiliary plans of saving water, and recycling used water should be treated as improvement principles.

5. Population growth and industrial changes are among the factors that highlight the importance of water resources. In addition to insufficiency of water supply, the quality of water resources affects water utilization as a whole. The quality of water resources in the surveyed region should be strengthened. Excessive eutrophy of the reservoir not only affects water allocation, but also increases costs of disposing water. Meanwhile the pollution of rivers and other bodies of water can affect environmental ecology and people's lives. 


\section{Acknowledgement}

We hereby express special thanks to the National Science Council (Plan No. of NSC 97-2621-M-426-003) for the funds granted, which allowed for the successful completion of this study.

\section{References}

[1] Dong, Z. C., Allocation of water resources in the western region, Water Resources and Hydropower Technology, 32(3), pp. 1-4, 2001.

[2] Falkenmark, M., Coping with water scarcity under rapid population growth. Pretoria: Conference of SADC Ministers, pp. 23-24, 1995.

[3] Gleick, P. H., Water in crisis: paths to sustainable water use. Ecological Applications, pp. 571-579, 1998.

[4] Jenerette, G. D., A global perspective on changing sustainable urban water supplies, Elsevier, pp. 202-211, 2006.

[5] Wan L. F, Lee Y. \& Zhuang, Y., Study on water resources bearing capacity indicator system, Soft Science, 21(6), pp. 8-14, 2007. (In Chinese)

[6] Wen, G., Water resources bearing capacity study in recent 10 years, Water Resources Protection, 21(6), pp. 15-18, 2005. (In Chinese)

[7] Zhang L., Water resources carrying capacity research progress and prospects, Water Resources and Hydropower Technology, 34(4), pp. 1-4, 2003. (In Chinese)

[8] Zhang, T., Xiao, J. \& Hu, H., Hunan province water resources analysis, Journal of Changsha Jiaotong University, 24(2), pp. 78-85, 2008. (In Chinese) 